\title{
Primary care counselling for injury prevention: where is the evidence?
}

\author{
Terry P Klassen
}

While counselling for injury prevention in the primary care setting many sound like a good idea, especially with health promotion and preventative health coming more into vogue, it is important to critically examine the evidence for the effectiveness of such interventions before merely embracing them because they are popular. Such a critical examination is essential because, in an era of increasing cost restraints, engaging in activities with no proved effectiveness may be wasteful. In addition, education may at times do more harm than good, evidenced by the example of increased crash rates after high school driver education. ${ }^{1}$

There are two main problems with the existing evidence - the quality of the evidence and the choice of outcome measures. Quality of evidence is lacking from existing trials because few of them are randomized controlled trials, and many lack complete follow up. Quality of evidence is important because it determines how much confidence can be placed in these results. Non-randomized studies and studies where participant follow up is not complete result in data that are prone to bias. Hence, less confidence can be placed in these results. The other major problem is the frequent choice of intermediate outcome measures such as behavioural change, in current studies, rather than the measuring of reductions in injury rates or the severity thereof.

Are these criticisms fair? I believe they are and that injury prevention research must meet the standards set for health care research in general. To do less will only hurt our reputation as credible researchers in the health care field. It is now generally believed that the randomized controlled trial is the most valid method for examining new health care interventions. Indeed, a new drug would have little chance for acceptance by the medical community and regulatory bodies, unless it had undergone such rigorous evaluation. Should injury prevention research, and more particularly, should primary care prevention, in the siutation we are examining here, be required to undergo such evaluation before adoption into clinical practice? My answer would be yes in all cases where randomization is feasible due to the nature of the intervention. Randomization may be logistically impossible when the intervention involves legislation or some form of environmental modification. However, for an educational intervention such as primary care counselling, randomization is certainly feasi- ble, and methods such as cluster randomization, have been well developed by Donner et al for use in public health. ${ }^{2}$

What about the use of intermediate outcome measures such as behavioural change? Ultimately in injury prevention we are concerned with reducing injuries. Unless there is strong evidence linking behavioural change to injury reduction, limited information can be derived from such studies. For example, does home storage of ipecac reduce the morbidity from poisoning? ${ }^{3}$ The counter argument to adopting these outcome measures is that studies where injury rates are the primary outcome must have large sample sizes due to the need for statistical power to detect rare events (injuries), and hence are costly to complete. This is a serious consideration but one that researchers in this field must confront. The move toward utilizing rarer outcomes will demand larger trials and this has important implications for funding agencies. However, with many of these same funding agencies willing to fund large multicentre trials of middle aged men with heart disease, certainly an equal priority should be given to an intervention that could prove effective in saving the lives of young children. Such choices are up to society to make.

What types of interventions might be best suited to primary care counselling based on theories such as the health belief model or PRECEDE? Those interventions that require a simple action such as lowering the temperature of the hot water tank would be most likely to be successful. ${ }^{4}$ Primary care counselling may also provide an excellent opportunity for reinforcing strategies, if children and their parents are being seen on a regular basis. Therefore the theoretical basis for primary care counselling provides some rationale to explore such interventions in a more rigorous fashion.

However, until strong evidence is provided showing that primary care providers can reduce the severity and number of injuries to children by counselling, they should utilize their time in performing activities that have proved to be effective. For injury researchers there is a call to provide such evidence, so that if indeed injury control interventions in the primary care setting are effective, primary care providers can embark on utilizing the evidence and in making the best use of limited health care resources. 
1 Lund AK, Williams AF, Zador PL. High school driver education: further evaluation of the DeKalb County education: further evaluation of the DeKal
study. Accid Anal Prev 1986; 18: 349-57.

2 Donner A, Birkett N, Buck C. Randomization by cluster: sample size requirements and analysis. Am $\mathcal{f}$ Epidemio 1981; 114: $906-14$
3 Kelly B, Sein C, McCarthy PL. Safety education in a pediatric primary care setting. Pediatrics $1987 ; 79$ 818-24.

4 Katcher ML, Landry GL, Shapiro MM. Liquid-crystal thermometer use in pediatric office counseling about tap water burn prevention. Pediatrics 1989; 83: 766-71.

\section{Editorial Board Members: brief biographies}

These brief biographies are intended to introduce our readers to members of the editorial board. We intend to include several in each issue. Watch this space.

\section{RAJAN KRISHNAN}

Dr R Krishnan completed his undergraduate and postgraduate training in paediatrics at the Christian Medical College, Vellore, South India.

Joined as lecturer in the Department of Paediatrics at the University of Malaysia in 1982. Received Fellowship of the Royal Australian College of General Practitioners in 1988. Appointed to the Department of Primary Care Medicine in 1992 and promoted to Associate Professor in 1994.

Past Chairman, Accident Prevention Committee, Malaysian Medical Association. Past Chairman, Injury Prevention Subcommittee Malaysian Medical Association. Member, Research Evaluation and Development Subcommittee, Road Safety Council of Malaysia. Currently Head, Department of Primary Care Medicine, University of Malaysia.

Research interests: childhood injuries - motorcycle/ bicycle injuries.

\section{DAVID BASS}

Graduated MB, ChB University of Cape Town in 1977. Trained at Groote Schur Hospital in general surgery 1981-94, graduating Fellow of The College of Surgeons in 1984 and Master of Medicine (Surgery) in 1997.

Since 1987-present, has been head of Paediatric Trauma Service at Red Cross Children's Hospital and a Senior Lecturer in the Department of Paediatric Surgery. Also acting Director of The Child Accident Prevention Foundation of Southern Africa and member of the national board of the foundation.

Has published papers on topics in general surgery, paediatric trauma, general pediatrics, child abuse, and injury prevention.

Special interests: paediatric head injury, road safety, forensic medicine related to trauma, advanced life support training and techniques. 